\title{
Transposições Fúlmicas de Histórias em Quadrinhos: Uma teorização da relação entre duas linguagens
}

\author{
Yuri Garcia \\ Universidade do Estado do Rio de Janeiro (Programa de Pós-Graduação em Comunicação)/ Universidade \\ Estácio de Sá (Programa de Pesquisa e Produtividade) \\ yurigpk@hotmail.com \\ https://orcid.org/0000-0003-1077-5929
}

RESUMO Este artigo busca estabelecer relações entre as linguagens do cinema e dos quadrinhos em uma abordagem teórica. As transposições de histórias em quadrinhos - sobretudo de super-heróis - vêm se tornando um grande mercado da indústria cinematográfica. Essas produções costumam ser acompanhadas de um grande orçamento e grandes bilheterias, se firmando entre os maiores blockbusters da história. Assim, essa tendência parece ganhar um crescente espaço em Hollywood. Além do fator financeiro, que se destaca como um elemento essencial nas escolhas das grandes produções cinematográficas, os filmes em questão parecem estabelecer novas possibilidades ao iniciarem um processo de maior aceitação crítica. Dessa forma, uma investigação desse fenômeno em sua configuração mais gramatical pode fundamentar algumas hipóteses que apontem os motivos pelos quais o cenário contemporâneo se apresenta como o melhor momento para as histórias em quadrinhos serem transpostas para o cinema.

PALAVRAS-CHAVE Cinema; histórias em quadrinhos/ banda desenhada; transposições; linguagem; teoria.

\section{Introdução}

O universo das histórias em quadrinhos tem alcançado um crescente e massivo espaço no meio audiovisual norte-americano. Com uma forte tendência, que parece ganhar cada vez mais força, os filmes baseados em super-heróis oriundos de revistas se tornam uma fórmula que raramente não se concretiza em um sucesso de público com grandes retornos financeiros para as suas produtoras. Apesar dos atuais blockbusters fílmicos versarem muito em torno dessa aliança intermidiática, tal processo não é algo que tenha surgido recentemente. Desde seus primórdios, o cinema se utiliza de histórias de diversas 
outras mídias. Além da literatura e do teatro, também as histórias em quadrinhos foram um rico material para a criação de filmes logo desde o seu surgimento. No entanto, esse diálogo se consolidou como uma fórmula de maior sucesso apenas nos últimos anos.

Sem descartar a repercussão de outras produções anteriores, é, então, importante ter em conta que apenas recentemente temos uma utilização massiva de um amplo universo das histórias em quadrinhos na indústria hollywoodiana. Até há pouco tempo, essa apropriação se reduzia a alguns casos específicos e, apesar do sucesso de SuperHomem (sobretudo em 1978, 1980 e 1983) e de Batman (em 1989, 1992 e 1995), inúmeros outros super-heróis naufragavam em fracassos de bilheteria e/ou não possuíam um suficiente investimento que possibilitasse o financiamento de um projeto mais ousado. O atual universo cinematográfico da Marvel Comics foi apresentado pela primeira vez há pouco mais de 10 anos, com Iron Man (2008). Mesmo se contarmos os filmes não pertencentes a essa linha do franchise, mas oriundos da mesma editora de quadrinhos, Spider-Man (2002) e X-Men (2000), nos encontramos em um espaço de tempo de cerca de 20 anos. Assim, podemos destacar, independente da perspectiva adotada, que esse fenômeno se manifesta com maior potência a partir dos anos 2000 e que tem apresentado melhores possibilidades em termos de reconhecimento crítico mais recentemente. Trata-se de um fenômeno extremamente contemporâneo que se encontra em crescente sintonia com seu público e com nossa sociedade. ${ }^{1}$

Embora a recente vaga de transposições não se cinja apenas ao universo cinematográfico dos super-heróis, essas produções ocuparão um lugar central na linha argumentativa deste artigo. As histórias em quadrinhos de heróis da DC Comics e Marvel Comics se sobressaem enquanto corpus analítico pelo seu destaque mercadológico (tanto de produção quanto de recepção) e por sua repercussão crítica (visto que são filmes que ocupam um espaço de grande visibilidade midiática). Assim, o recorte do artigo será as produções hollywoodianas live-action de super-heróis dessas duas grandes empresas como uma tendência mercadológica contemporânea. Essa decisão não procura delimitar o

\footnotetext{
${ }^{1}$ A maior bilheteria da história do cinema até o presente momento foi Avengers: Endgame (2019). Dentro da lista das maiores 10 bilheterias, contamos com 3 filmes baseados em HQs. Estendendo a análise, podemos perceber um total de 10 filmes entre as 30 maiores bilheterias da história do cinema (os 10 sendo filmes de super-heróis). Fonte: https://www.boxofficemojo.com/chart/top_lifetime_gross/?area=XWW (consultado em: 17 de fevereiro de 2021).
} 
campo analítico para casos específicos, mas compreende que esse fenômeno possui uma amplitude e diversidade de outros gêneros e formatos que também ganham maior espaço no cenário contemporâneo (e possuem suas complexidades e especificidades próprias).

Em um contexto em que a pluralidade das mídias, assim como seus diálogos, se encontra em constante ascensão, a relação entre cinema e histórias em quadrinhos se apresenta como uma relevante investigação. Nesse cenário, em que concepções como a de "modernidade líquida" (Bauman 2001) se popularizam, ao identificar a fluidez e efemeridade como predominantes na forma de consumo e relacionamento do sujeito pós-moderno, a sobrevida do universo das histórias em quadrinhos como principal produto cinematográfico das grandes produções e grandes bilheterias perdura com certo prazo de validade. Nesse sentido, percebemos vários gêneros cinematográficos hollywoodianos ocupando esse estatuto ao longo da história - como os musicais e os westerns nas décadas de 1930-60, os épicos nas décadas de 1950-60 e o cinema de ação nas décadas de 1980-90. Liam Burke (2015) argumenta que as transposições de histórias em quadrinhos se tornaram um novo gênero cinematográfico. Apesar de sua hipótese ser bem fundamentada em seu arcabouço teórico - sobretudo em seu segundo capítulo - e seu livro ser um estudo minucioso desse fenômeno contemporâneo, consideramos esse debate ainda demasiado recente e mais complexo. É necessário destacar que os gêneros são formados em torno de características específicas que remetem mais ao processo narrativo, estético e estilístico do que ao meio de comunicação de onde suas histórias se originam. Além disso, a própria concepção de gênero faz parte das variações encontradas dentro das histórias em quadrinhos e de vários filmes provenientes dessas narrativas. Dessa forma, para esse trabalho, compreendemos os filmes de super-heróis baseados em histórias em quadrinhos não como um novo gênero, e sim como um fenômeno de transposição que parece se apropriar de uma pluralidade de elementos de variados gêneros sobretudo ação, aventura e fantasia.

Em termos mercadológicos, as transposições fílmicas de histórias em quadrinhos parecem dialogar com os ciclos de popularidade dos gêneros cinematográficos. Ao permanecer durante duas décadas sob os holofotes mainstream, esses filmes se firmam como grandes sucessos de bilheteria e evocam fórmulas e tendências que são reconfiguradas em 
variadas produções. Além disso, passam a gozar de produções consideradas mais artísticas, com reações favoráveis da crítica cinematográfica e frequentes premiações em diversos festivais. ${ }^{2}$ A onda de popularidade parece, então, tomar proporções maiores e se consolidar como um mercado duradouro. Nesse sentido, a repercussão econômica desse fenômeno se constitui como importante foco de estudo. Todavia, sua amplitude não se restringe ao recorte mercadológico. Em outro viés analítico, a própria relação entre as mídias em termos de linguagem se apresentará como um elemento central do presente artigo.

No campo teórico, trata-se de um diálogo sobre mídias de extrema relevância epistêmica, possuindo ambas grande importância na história da comunicação. O cinema é uma das mais clássicas formas de se abordar o fenômeno comunicacional, servindo como objeto para as mais variadas análises e teorias. Já no início dos estudos na área, enquanto a comunicação se tornava uma importante forma de compreender a sociedade, Herbert Blumer (1933) apresentava uma pesquisa feita com financiamento do Fundo Payne para demonstrar a forte influência que os filmes possuíam na formação das pessoas. Embora as histórias em quadrinhos sejam uma área de menor concentração científica em comparação com o cinema, ocupam um espaço relevante, tanto historicamente quanto como objeto de estudo. Com um campo emergente, ainda não tão fortemente formalizado como o cinematográfico, e com menos mercado, também os quadradinhos encontraram uma vertente de nicho acadêmico. Nesse quesito, o processo de legitimação do campo se apresenta como uma questão de grande destaque em seus estudos. Marc Singer (2018) aponta como alguns de seus teóricos promovem um comportamento militante e/ou celebratório da importância e qualidade dos quadrinhos, ao invés de se dedicar a uma investigação analítica e aprofundada do objeto e do processo metodológico empregado. Embora a problemática apontada pelo autor não perpasse o objetivo deste trabalho, contribui de forma eficiente para a demonstração do panorama atual das pesquisas em histórias em quadrinhos.

\footnotetext{
${ }^{2}$ Nesse sentido, podemos compreender The Dark Knight (2008) de Christopher Nolan como um importante marco, ao ser indicado em 8 categorias no Oscar de 2009, tendo levado as premiações de 'Melhor Ator Coadjuvante' para Heath Ledger e 'Melhor Edição de Som' para Richard King. Em um cenário mais recente, filmes como Logan (2017), Black Panther (2018) e Joker (2019) têm sido indicados nas premiações dos óscares e outros festivais.
} 
No cenário brasileiro, a dificuldade de legitimação recai em um contexto específico que perpassa diversas complexidades que o país apresenta. A problemática, todavia, possui contornos similares. Mesmo percebendo um aumento de trabalhos e eventos que abordam o assunto, diversos teóricos apontam para o mesmo problema em sua trajetória. No livro organizado por Vergueiro, Ramos e Chinen (2013) sobre os estudos de quadrinhos no Brasil, pesquisadores como Álvaro de Moya, Antonio Luiz Cagnin, José Marques de Melo, Moacy Cirne, Sonia Bibe Luyten e Waldomiro Vergueiro contam a dificuldade que passaram e a rejeição que sofreram inicialmente, ao propor trabalhar sobre esse meio. Mesmo as recentes edições do congresso brasileiro Jornadas Internacionais de Histórias em Quadrinhos mantêm esse debate como uma de suas principais pautas, com novos pesquisadores continuando a salientar a dificuldade de recepção das suas pesquisas. ${ }^{3}$

As transposições para o cinema parecem permitir um aumento da visibilidade dos quadrinhos. Apontar esse diálogo como responsável pela expansão do campo acadêmico seria, contudo, meramente especulativo e simplista. O que pode ser mais claramente percebido, de forma mais empírica, é sua vertente econômica. Nesse sentido, a relação entre as histórias em quadrinhos e o cinema parece ser frutífera para ambos os meios. O cinema tem gozado de enormes bilheterias com estas transposições, enquanto o mercado quadrinístico parece se alavancar com a publicidade de seus personagens e suas narrativas no meio audiovisual, desenvolvendo-se uma produção transmidiática. Dessa forma, a própria pesquisa sobre a relação entre os meios ganha mais espaço. O presente artigo pretende então traçar algumas aproximações entre esses dois meios, destacando aspectos de suas linguagens. A primeira secção apresenta a relação entre histórias em quadrinhos e cinema, traçando um panorama geral dos seus elementos históricos e desenvolvendo já algumas articulações de caráter mais teórico. Similaridades entre os dois meios através de autores específicos e questões de linguagem e conteúdo também serão abordadas, a fim de prover uma visão mais completa desse fenômeno. A segunda secção tem como foco discutir algumas diferenças e dificuldades, debatendo o processo de transposição através de

\footnotetext{
${ }^{3} \mathrm{O}$ evento, sediado pela Universidade de São Paulo (USP), contou com sua $6^{\mathrm{a}}$ edição em 2019. A USP possui uma longa tradição de pesquisas sobre histórias em quadrinhos, tendo, inclusive, criado um centro de pesquisas (Observatório de Histórias em Quadrinhos ECA/USP) e disciplinas sobre o assunto na década de 1970 que perduram na instituição até o presente momento.
} 
observações mais técnicas e abordando o cenário mais recente de produções fílmicas e pesquisas específicas sobre o assunto. Esta discussão de similaridades e diferenças na relação entre cinema e histórias em quadrinhos evidenciará questões em torno da popularização das transposições live-action das histórias de superheróis, um processo que não parece estar alcançando seu período conclusivo, mas sim abrindo novas possibilidades. A secção final contém considerações sobre as mais recentes mutações deste campo, demonstrando que este objeto de estudo se trata de um fenômeno em constante transformação e reconfiguração.

\section{A relação entre cinema e histórias em quadrinhos}

A história do cinema é marcada por um permanente diálogo com outras mídias. Desde seus primórdios, também conhecidos como "primeiro cinema”, vemos um constante processo de histórias advindas de outros meios sendo transpostas para as telas. Ainda em busca de uma maturidade como meio, o cinema procurava conquistar mais espectadores e começava a se preocupar em atrair também um público de maior poder aquisitivo. Dessa forma, procura oferecer uma familiaridade maior à audiência, com finalidade de aumentar o retorno financeiro de suas exibições, contando com uma classe que pudesse pagar um valor mais elevado nos ingressos. Assim sendo, as histórias mais conhecidas tornam-se uma importante fonte de material fílmico. Entre elas, os livros e as paixões de Cristo eram os grandes destaques (Costa 2005). A relação entre literatura e cinema é intrínseca desde os primórdios do meio, mas outros meios de comunicação também se apresentavam nesse diálogo: já em 1895, os irmãos Lumière exibem L'Arroseur Arrosé, baseado em uma tirinha de jornal, uma representação imagética que é considerada um dos primórdios das histórias em quadrinhos. ${ }^{4}$

Enquanto os livros em prosa ganhavam cada vez mais espaço como uma das maiores fontes de material para desenvolvimento de filmes, o diálogo com as histórias em quadrinhos se dava de forma mais tímida. Apesar de alguns personagens como Batman e Super-Homem estarem em constante diálogo com o cinema, o espaço destinado a outros

\footnotetext{
${ }^{4}$ Para mais detalhes sobre o início das histórias em quadrinhos, ver Gordon (1998).
} 
produtos ainda era relativamente pequeno. ${ }^{5}$ Esse processo de adaptação se manteve tímido durante muitos anos, com aparições ocasionais de alguns personagens mais famosos. ${ }^{6}$ Entretanto, nas últimas décadas, esse cenário se modificou. O diálogo entre cinema e quadradinhos temse transformado em uma grande tendência em nossa cultura contemporânea. Em um levantamento de dados complementar a esse trabalho, percebemos que até 1979, nos Estados Unidos da América, só haviam sido feitos 16 longas-metragens baseadas em histórias em quadrinhos (sendo 6 deles produzidos diretamente para a televisão). A década de 1980 conta com um aumento significativo, com um total de 18 filmes em 10 anos. Na década seguinte, o aumento parece continuar, com 44 produções. No entanto, entre 2000 e 2020 temos 140 produções, com as narrativas de heróis como seu maior foco mercadológico, conseguindo se destacar com mais de 20 produções entre as 100 maiores bilheterias da história do cinema. ${ }^{7} \mathrm{O}$ fenômeno da “cauda longa" descrito por Chris Anderson (2006) indica um aumento de rentabilidade dos mercados de nichos, observando que estratégias de venda que tenham como foco produtos de menor demanda podem ter bons lucros - visto que estes existem em uma abundância maior (e têm muitas vezes menos competidores) do que os produtos de grande destaque. A análise de Anderson ajuda a compreender a importância dos fãs de quadrinhos para o consumo das transposições fílmicas, pois, em um espectro cinematográfico mais amplo, poderíamos identificar esse segmento como uma parcela fiel dentro das milhões de pessoas que assistem a filmes. Todavia, o mercado cinematográfico não possui como público central os fãs de quadrinhos. Mesmo com alguns filmes versando essa realidade mais específica, de uma forma geral esse fenômeno alcançou outro estágio financeiro e de audiência principalmente se tratando das grandes produções de histórias de super-heróis.

\footnotetext{
${ }^{5}$ Nesse caso, é necessário relembrar que o recorte proposto tem como foco o cinema hollywoodiano e a concepção ocidental de histórias em quadrinhos. A relação entre o cinema e os mangás, assim como com qualquer cinematografia fora do eixo hollywoodiano não faz parte desta análise, por possuir características muito específicas da cultura e do mercado de cada país.

${ }^{6}$ É importante ressalvar que as adaptações não se limitavam, especificamente, ao universo dos superheróis. No entanto, costumavam centrar suas narrativas em torno de gêneros como aventura e/ou fantasia - Flash Gordon (1980) e Teenage Mutant Ninja Turtles (1990) - ou comédia - Dennis the Menace (1993) e Richie Rich (1994).

${ }^{7}$ https://www.boxofficemojo.com/chart/top_lifetime_gross/?area=XWW (consultado em 17 de fevereiro de 2021).
} 
Um aspecto de extrema importância é a complexidade de transpor um universo tão fantasioso para o meio audiovisual. Nesse caso, o aprimoramento tecnológico que ocorre atualmente possibilita uma ampliação do mercado cinematográfico em termos de qualidade e de quantidade. Erick Felinto (2006, 214) aborda como o avanço tecnológico impacta o cenário cinematográfico contemporâneo, tanto em termos criativos como mercadológicos: "A introdução das tecnologias digitais facilitou imensamente os processos do cinema industrial e massivo, ao mesmo tempo em que ampliou possibilidades estéticas e abriu novos caminhos aos realizadores independentes”. Essa ideia pode ser facilmente aplicada ao caso aqui em estudo.

Ainda assim, no caso das transposições de histórias em quadrinhos, o recurso tecnológico não se configura como um fator determinante, visto que o diálogo entre as mídias em questão se iniciou há mais de cem anos. Outro aspecto que poderia se configurar como um indicativo da não-exclusividade do desenvolvimento tecnológico é o amplo mercado de produções independentes que não se amparam com tamanha ênfase nesses recursos, assim como as propostas mais experimentais e/ou mais focadas em outras possibilidades de transposição dos quadrinhos como Ghost World (2001) e Art School Confidential (2006) de Terry Zwigoff e American Splendor (2003) de Shari Springer Berman e Robert Pulcini. No entanto, quando trazemos o recorte para o meio dos blockbusters, esse fator ganha maior peso. $\mathrm{O}$ que podemos perceber é que esse elemento parece possibilitar uma amplitude maior na criação do universo fantasioso de determinadas obras que contavam com cenários e cenas de ação específicos de uma linguagem das histórias em quadrinhos e que ainda não parecia ser possível configurar de forma realista.

É importante destacar que essa concepção de realismo atribuída ao cinema se encontra calcada, sobretudo, em sua ontologia fotográfica, que permite uma aproximação maior no método de representação visual de pessoas, objetos e lugares. O debate sobre a noção de realismo possui uma longa tradição que perpassa os campos das artes, da estética e da filosofia. Por uma necessidade de maior objetividade argumentativa, nesse trabalho, utilizaremos o recorte proposto por Tânia Pellegrini:

Assim, creio que hoje ainda se pode usar com proveito o conceito de 'realismo' para significar uma tomada de posição diante de novas realidades (postura), 
expressas justamente na característica especial de observação crítica muito próxima e detalhada do real ou do que é tomado como real (método), que em literatura não só a técnica descritiva representou e muitas vezes ainda representa, ao lado de outras, podendo, deste modo ser encontrada em várias épocas, como refração da primeira. (Pellegrini 2008, 149)

Nesse sentido, podemos compreender como "postura" o universo narrativo trabalhado em ambos os meios, onde um grau fantasioso maior é atribuído às histórias dos quadrinhos do que às do cinema. No quesito "método", temos a diferenciação no processo de desenhar e fotografar como seu emblema central. Dessa forma, evitando um debate filosófico sobre a concepção de realidade e a crise da representação, utilizamos o termo para fins pragmáticos e expositivos baseados nas características específicas dos meios citados. O avanço tecnológico permitiu, então, a reprodução de um universo quadrinístico de forma mais similar ao de sua fonte primária. Ao invés de procurar compreender a narrativa e reconfigurar sua estrutura para o cinema, algumas transposições contam com uma quase reprodução dos quadros impressos dos quadrinhos em um formato live-motion como no caso de Sin City (2005).

Relacionado com este processo, um outro elemento revela-se essencial para o crescimento do fenômeno em estudo: a compreensão da adequação entre diferentes linguagens. Para isso, devemos compreender o diálogo intermidiático em seu aspecto mais gramatical, focando mais na parte de linguagem e conteúdo. Jay Bolter e Richard Grusin (2000) reforçam a inspiração mcluhaniana de que as novas mídias trazem elementos de mídias anteriores. ${ }^{8} \mathrm{~A}$ articulação central dos autores não apresenta sua argumentação apenas em torno da gramática e linguagem, mas também desenvolve seu foco nos produtos - principalmente quando adentra o próprio processo de transposição exemplificado através de adaptação de romances literários de Jane Austen para o cinema.

Drew Morton (2016) se apropria da articulação central de Bolter e Grusin (2000) para desenvolver seu conceito de "remediação

\footnotetext{
${ }^{8}$ A relação da obra dos autores com McLuhan fica mais evidente ao observarmos a referência ao teórico canadense no próprio subtítulo, através de uma homenagem ao seu mais famoso livro, Understanding Media, publicado pela primeira vez em 1964 e traduzido no Brasil como Os Meios de Comunicação como Extensões do Homem (2007).
} 
estilística”. O autor analisa a relação entre histórias em quadrinhos e cinema, apontando como seu foco principal os diálogos estilísticos entre os meios e não o processo de adaptação, o qual indica como diferente do processo de remediação. Morton desenvolve uma leitura da obra de Bolter e Grusin mais próxima de sua proposta metodológica do que de uma compreensão mais plural da ideia apresentada pelos autores. Para reforçar sua afirmação, aponta alguns exemplos que indica como adaptação que não são remediações (sem explicações muito satisfatórias) - como a trilogia Batman, de Christopher Nolan.

Essa parte inicial do trabalho de Morton parece ignorar que o diálogo entre as mídias é muito mais amplo do que a dicotomia que procura estabelecer entre adaptação e remediação. Como foi dito acima, a relação entre histórias em quadrinhos e cinema se dá desde o surgimento dos meios, que possuem elementos ontológicos e estilísticos em comum desde o estabelecimento da linguagem narrativa clássica cinematográfica. Além do mais, apesar do foco do estudo de Bolter e Grusin não ser a questão das adaptações, os próprios autores tratam como remediação as adaptações de romances literários e, em momento algum, indicam qualquer diferenciação entre ambas. Morton propõe essa leitura do conceito dos autores de forma algo simplista em sua apresentação inicial do aspecto mais teórico de sua compreensão dessa ideia. Não obstante, mais à frente, a utilização do termo "estilístico" em sua argumentação parece fundamentar melhor sua metodologia e sua investigação da "remediação estilística" alcança maior força. O autor propõe a demonstração de como alguns elementos estéticos e discursivos dos dois meios em questão se atravessam de forma complexa, permitindo possibilidades interessantes tanto para os quadrinhos como para o cinema.

Podemos nos utilizar dessa análise entre os meios pelo prisma de McLuhan (2007) e suas releituras contemporâneas - como as apontadas anteriormente - como um arcabouço conceitual central para compreender que a relação intermidiática em causa ocorre não apenas em termos de transposição, mas também pela utilização de elementos da linguagem de outras mídias. Nesse quesito, é interessante perceber que tanto o cinema quanto as histórias em quadrinhos possuem uma outra mídia em comum em termos de estruturação inicial de sua linguagem. Em ambos os casos, a invenção tecnológica ou mesmo artística decorre de uma remodelação de elementos gramaticais de um meio que predominava com certa exclusividade ao longo dos tempos: a 
literatura. Tendo se apropriado de seu composto narrativo em sua estrutura básica, as três mídias se assemelham em sua forma de contar histórias.

Uma das dificuldades iniciais na compreensão dos primórdios das histórias em quadrinhos está na determinação do que se configura como primeira história em quadrinhos em sua dissociação da ideia de literatura ilustrada. De uma forma geral, reconhece-se a obra Yellow Kid (1896) de Richard Felton Outcault como a precursora. Esse marco inicial é estabelecido a partir de um recorte que evidencia o pioneirismo norte-americano e acaba sendo alvo de um amplo campo de debate baseado no que caracterizaria, exatamente, uma história em quadrinhos (Vergueiro 2015). Se retornarmos à afirmação de que a primeira transposição cinematográfica seria L'Arroseur Arrosé, podemos perceber uma dificuldade inicial de confirmar a versão norteamericana. Esse filme, dirigido por Louis Lumière, data de 1895, um ano antes da publicação de Yellow Kid, e é baseado nas tirinhas L'Arroseur de 1887 de Hermann Vogle (Burke 2015, 3). Além disso, algumas evidências já indicam narrativas que podem ser consideradas precursoras, como As Aventuras de Nhô Quim de Angelo Agostini, em 1869, considerada a primeira história em quadrinhos no Brasil. Ian Gordon (1998) destaca que a concepção acima referida costuma ser fundamentada em um recorte metodológico que compreende as histórias em quadrinhos como uma arte fundamentalmente estadunidense. $\mathrm{O}$ autor, no entanto, destaca a multiplicidade de formas quadrinísticas que surgiam, sobretudo, na Europa e prefere relacionar os Estados Unidos ao desenvolvimento de um modelo de consumo de massa imagético no qual os quadrinhos possuem um papel determinante. Essa breve explanação não tem como intuito desenvolver o problema em torno da afirmação do pioneirismo norteamericano, mas sim levantar a questão sobre a dificuldade em apontar esse recorte inicial das histórias em quadrinhos.

O diálogo com a literatura pode ser retomado como uma relação de emancipação que se concretiza no momento em que as histórias em quadrinhos surgem no seio da mídia impressa. A configuração jornalística se faz presente na estruturação das primeiras histórias (visto fazerem parte do jornal impresso), assim como o elemento pictórico, por se tratar de uma mídia desenhada. Will Eisner (1989) identifica as histórias em quadrinhos como "arte sequencial", o que implica diretamente na questão da compreensão narrativa proposta 
através da leitura de imagens e textos sendo expostos em sequência de forma ordenada. Dessa maneira, podemos compreender esse aspecto do desenvolvimento de sua linguagem como uma inovação do meio impresso (seja em livros ou jornais). Uma utilização imagética que já se encontrava na literatura ganha agora forma como um elemento determinante e não apenas auxiliador na narrativa.

O cinema, por outro lado, surge como um invento cujo foco inicial era o de se demonstrar enquanto tecnologia, sem muita preocupação narrativa, como podemos ver na concepção de “cinema de atrações”, de Tom Gunning (2006). Depois de um período de experimentação de suas potencialidades, esse aspecto narrativo que predomina na atualidade é desenvolvido como elemento central de sua linguagem. Assim, o cinema surge com sua função de exposição de uma possibilidade maravilhosa de demonstração da imagem em movimento através da câmera (Machado 2014).

Ao passar de invento tecnológico para aquilo que ficou conhecido como "sétima arte", 9 a apropriação de elementos de mídias anteriores se tornou essencial para a composição do cinema. Assim sendo, o aspecto cênico do teatro e a estrutura narrativa da literatura fundamentam a linguagem cinematográfica. O componente literário se mostra muito evidente tanto no aspecto de transposição (apontado anteriormente) quanto na própria configuração e montagem de sua forma de contar a história. Não por coincidência, o "Era uma vez" dos livros é utilizado como início de diversos filmes (em alguns casos chegando a aparecer a imagem da página de um livro iniciando a narrativa fílmica) e até nos títulos de variadas obras audiovisuais, como Era uma Vez no Oeste (1968) ou Era uma Vez na América (1984).

Essa base literária em comum já aponta para diversas similaridades entre os dois meios. Podemos, ainda, destacar que o cinema se utiliza tanto da linguagem literária quanto da imagética textual das histórias em quadrinhos em seu processo de produção e pré-produção. Com o roteiro cinematográfico sendo muito próximo de um livro (apesar das diferenças mais estruturais e a preocupação descritiva de elementos técnicos e cênicos), muitos realizadores utilizam storyboards, que se

\footnotetext{
${ }^{9}$ Para mais detalhes sobre a legitimação do cinema enquanto arte, conferir o ensaio sobre impressionismo francês, de Fernanda A. C. Martins (2006).
} 
assemelham com a linguagem das histórias em quadrinhos, para suas gravações.

Retomando o foco mais conteudístico, outro aspecto essencial seria a apropriação de uma base teórica de estudo de estrutura narrativa em comum entre cinema e histórias em quadrinhos. Publicado pela primeira vez em 1949, O Herói de Mil Faces (1989), de Joseph Campbell apresenta a "Jornada do Herói”, um arco narrativo baseado no conceito de arquétipo de Jung (2018) atrelado a um mapeamento de elementos encontrados na narrativa do herói em diferentes culturas. O livro de Campbell acaba se tornando uma fonte muito utilizada para o desenvolvimento de material dos dois meios. No que diz respeito ao cinema, converte-se em uma espécie de manual de roteiro ou de formas de desenvolvimento de personagens e arcos dramáticos (é amplamente estudado em cursos de cinema, principalmente de roteiro, sendo notório o facto de George Lucas dizer que baseou a saga de Star Wars no livro de Campbell). Já nos quadrinhos, a constância da figura do herói como seu principal protagonista bastaria para atestar essa relação, ${ }^{10}$ mas a própria estrutura que Campbell apresenta acaba se tornando uma espécie de manual também para a construção do texto quadrinístico e/ou de seus personagens. ${ }^{11}$

Além desse material em comum em seu conteúdo, a relação entre ambas as linguagens costuma ser aproximada por diversos autores. É interessante perceber que, no cenário acadêmico, essa relação se desenvolve de uma forma curiosa desde os primórdios dos estudos em quadrinhos. Com a legitimação de seu campo mais estabelecida, o cinema já apresentava na década de 1960 variadas correntes teóricas e formas de análise fílmica. Assim, em 1965, na primeira publicação do renomado Apocalípticos e Integrados, Umberto Eco apresenta uma análise de um trecho das histórias em quadrinhos de Steve Canyon através de elementos da semiótica e de análises fílmicas, com um vocabulário herdado da linguagem cinematográfica, tratando os quadros como enquadramentos cinematográficos e usando termos como "enquadramento subjetivo" e "câmera recuou e panoramizou" (Eco 2006, 131; 134). Eco acaba sendo o primeiro grande autor a

\footnotetext{
${ }^{10}$ É importante destacar que essa "constância" não indica exclusividade, visto que as narrativas quadrinísticas não são apenas voltadas à figura do herói. No entanto, o imaginário popular das histórias em quadrinhos reverbera, principalmente, em torno dos super-heróis, que continuam sendo o maior produto das maiores empresas de histórias em quadrinhos estadunidenses - Marvel Comics e DC Comics.

${ }^{11}$ Para mais detalhes, conferir as dissertações de José Messias (2012) e Sabrina da Paixão Brésio (2016).
} 
apresentar a relevância dos estudos em quadrinhos em uma obra pertencente ao campo teórico da comunicação. ${ }^{12}$ Além da leitura de Steve Canyon, dedica uma grande parte de seu livro ao estudo de mais um personagem dos quadrinhos, o Super-Homem.

Eco abre passagem para uma gama de pesquisas sobre histórias em quadrinhos e demonstra a aproximação entre as linguagens como uma linha investigativa relevante que continua sendo utilizada atualmente. Álvaro Moya destaca essa aproximação com o cinema em seu relato como pesquisador: "Nós sabíamos que os quadrinhos eram literatura e que eles tinham as mesmas tomadas como no cinema" (Moya 2013, 30). A relação entre suas linguagens perpassa apenas suas similaridades com o meio literário e recai no próprio processo analítico pelo qual o campo dos estudos em histórias em quadrinhos se desenvolveu.

O atual fenômeno mercadológico de sucesso das transposições de quadrinhos de super-heróis para o cinema pode se configurar, aparentemente, como uma etapa lógica nesse processo. De um lado, percebemos a própria linguagem dos quadrinhos sendo utilizada em alguns filmes como os da franquia John Wick (Garcia, Monsores e Mangia 2020). Drew Morton (2016) aponta como The Matrix (1999) e até The Good, the Bad and the Ugly (1966) - em uma ousada análise do autor - já propunham uma estética similar à quadrinística, demonstrando que, apesar de sua grande popularização e intensificação na atualidade, esse processo dialógico já existia anteriormente. Porém, Morton identifica que vivemos uma era em que essa relação ganha contornos maiores e mais complexos com diálogos intermidiáticos - ou transmidiáticos, conceito que utiliza segundo a perspectiva de Jenkins (2009) - cada vez maiores.

Além do aspecto linguístico e estético que Morton propõe analisar, as transposições cinematográficas de histórias em quadrinhos alcançam um crescente espaço na crítica e em termos de bilheteria. Talvez o massivo uso das narrativas transmidiáticas em uma crescente convergência midiática como proposto por Jenkins (2009) ateste um

\footnotetext{
${ }^{12}$ A obra, além de trazer um importante debate sobre o viés epistemológico dos estudos de comunicação com suas críticas tanto à Escola de Frankfurt quanto às escolas norte-americanas -, desenvolve sua argumentação teórica sobre o que era compreendido como "cultura de massa" e "cultura aristocrática" como dimensões interligadas que se referenciam. O autor prefere o termo "comunicação de massa" e destaca a importância dos meios e manifestações artísticas mais "populares" para a produção cultural de uma determinada sociedade, assim como a necessidade em compreender os elementos linguísticos, o processo de recepção e o contexto no qual a produção e recepção da mensagem se encontra inserida.
} 
momento em que esse diálogo alcança seu ápice mercadológico. No entanto, acreditamos que tal fenômeno não se dá apenas pela óptica do consumidor e suas necessidades, mas também pelo próprio processo de compreensão da adequação de uma linguagem de um meio em outro.

\section{Transposições e linguagens}

Como apontado anteriormente no trabalho pioneiro de Umberto Eco, a aproximação com o cinema já se configurara como um processo inicial de recurso analítico das histórias em quadrinhos na área acadêmica. Atualmente, as similaridades entre esses meios continuam sendo analisadas por diversos teóricos, mas com um destaque maior também para suas diferenças, com a finalidade de conseguir demarcar melhor seus métodos de estudo.

Se, por um lado, é possível estabelecer semelhanças entre enquadramentos cinematográficos e os dos quadrinhos (um plano geral ou um close-up, por exemplo), cinema e histórias em quadrinhos possuem formas de codificação de narração, ritmo e temporalidades, entre outros aspectos, bem diferentes. (Santos 2015, 27)

Mesmo com alguns aspectos diferentes entre os meios, tamanhas similaridades deveriam apontar para uma maior facilidade no processo de transposição, já que, além do seu componente narrativo literário em comum, possuem proximidades estéticas nas próprias noções de plano e enquadramentos. No próprio aspecto mais teórico do procedimento de suas representações, ambos retratam a ideia de imagem em movimento. O cinema trabalha com essa percepção de forma mais explícita e sensorial através de uma ilusão óptica que passa a sensação de movimento em uma série de imagens fixas. Já os quadrinhos recaem nesse processo em um âmbito mais interpretativo que depende de um componente imaginário de seu leitor, que compreende essa movimentação como uma linguagem que transmite essa fluidez através de uma linearidade sequencial de quadros apresentados em ordem. Segundo Scott McCloud, o cinema se utiliza do tempo de projeção para demonstrar a passagem de seus quadros, enquanto as histórias em quadrinhos se utilizam do espaço físico das páginas: "Cada quadro de um filme é projetado no mesmo espaço - a tela - enquanto, nos quadrinhos, eles ocupam espaços diferentes" (McCloud 1995, 7). 
Essa questão já apresenta uma diferença na essência da apropriação entre os dois meios. A própria mudança de suporte já traz por si só um problema de adequação que faz com que algumas alterações sejam necessárias. Marcel Martin (2011) apresenta uma série de técnicas que fazem parte de uma gramática, uma linguagem que constitui o fazer fílmico. Apesar de existirem diversas formas mais heterodoxas de se utilizarem essas técnicas na constituição de um material audiovisual, de forma geral, essa utilização acaba se adequando a um padrão mais normativo e clássico hollywoodiano que se desenvolve em uma estrutura mais linear e de fácil compreensão. O cinema se adaptou a uma forma narrativa que busca uma simplicidade em sua linguagem. Não à toa, as experimentações cinematográficas ao longo da história contavam com um público mais reduzido e especializado.

É importante destacarmos que esse processo não é unilateral e as vontades e necessidades do público possuem influência direta no conteúdo dos produtos. Não excluímos a dicotomia entre os campos hegemônico e o contra-hegemônico, vista em diferentes estruturas da sociedade e sua forte propagação na indústria cultural. No entanto, em uma perspectiva mais contemporânea - talvez mais influenciada pela popularidade dos Estudos Culturais (Escosteguy 2010) -, acreditamos em uma constante negociação entre ambos os campos. Nessa negociação, vemos a linguagem cinematográfica se estruturando e evoluindo: de um lado, os cineastas procuram desenvolver suas obras da melhor forma possível; do outro, um público ávido por essas criações apresenta as mais variadas reacções a essas obras, influenciando e sendo influenciado por elas em uma relação multifacetada.

As experimentações técnicas se padronizaram em uma gramática cinematográfica e foram sendo acompanhadas teoricamente, desenvolvendo novas formas de fazer cinema. Bernadet (1985, 37-38) indica uma certa proximidade entre o discurso oral/escrito e o discurso fílmico em suas relações entre utilização prática (ou experimentação) e a construção epistêmica: "Partindo dessas operações linguísticas, teóricos tentaram escrever gramáticas cinematográficas, parecidas com as que se fazem para as línguas." O padrão empregado por Hollywood em seu período clássico ${ }^{13}$ trazia uma linguagem que, por meio de

\footnotetext{
${ }^{13}$ Para mais detalhes, ver Geada (1998).
} 
algumas evoluções, apresentava uma forma de se fazer filmes que perdura até ao presente. David Bordwell descreve essa estrutura narrativa cinematográfica hollywoodiana de forma resumida e explicativa:

O sistema clássico não é simplório. Devemos lembrar que, em condições normais de exibição, o nível de compreensão do espectador é absolutamente controlado. A construção de hipóteses prováveis, exclusivas e orientadas para o suspense é uma maneira de ajustar a dramaturgia às exigências da situação de fruição. O espectador não necessita reportar-se às sequências mais antigas do filme, porque suas expectativas estão direcionadas para o futuro. A exposição preliminar rapidamente estabelece os schemata, e a natureza "tudo ou nada" da maioria das hipóteses possibilita uma assimilação imediata das informações. A redundância mantém a atenção sobre o problema atual, ainda que uma sutil ausência de redundâncias possa permitir a ocorrência de pequenas surpresas posteriormente. No conjunto, a narração clássica administra o ritmo de fruição do filme solicitando ao espectador que elabore o syuzhet e o sistema estilístico de uma única forma: construindo uma fábula denotativa, unívoca e integral. (Bordwell 2005, 298)

Com o passar do tempo, algumas modificações começam a ocorrer no padrão narrativo clássico, absorvendo características que surgem em outras produções que não atuam tanto no mercado fílmico mais massivo, contudo, sempre mantendo uma forma que seja de mais fácil assimilação pelo público, sem fugir muito de uma lógica industrial de produção. Assim, como Aumont (2008, 94) aponta, apesar das reconfigurações e reinvenções ao longo de sua história, trata-se de um meio cujo foco é direcionado ao seu alcance massivo: "Ora, o cinema, apesar de todas as renovações, os aspectos, as crises, nunca mudou no facto de se dirigir à multidão."

Assim, a linguagem acaba sendo um aspecto essencial nesse percurso. Mas como aproximar duas linguagens que possuem tanto em comum, mas trabalham de formas diferentes? Como o foco principal deste artigo não é a investigação desse processo em todos os seus detalhes, aqui iremos tentar desenvolver mais algumas questões através da problemática apontada sobre as diferenças de apropriação entre os dois meios. Um elemento essencial que indica um problema inicial nessa adaptação é a diferença que ambas as mídias possuem na utilização do componente imaginativo em sua compreensão. Enquanto o cinema apresenta uma história mais encenada e, de certa maneira, mais pronta para seu público, as histórias em quadrinhos, apesar de indicarem a 
sequência imagética e narrativa em suas páginas, necessitam da imaginação do leitor para fazer essa ligação entre os quadros. Essa diferença aponta para uma forma narrativa que permite uma maior imaginação do público, simbolizando duas visões de mundo variadas. $O$ cinema live-action recai em uma maior necessidade de uma realidade mais compatível com o mundo em que vivemos, visto que o meio nos dá a impressão de movimento com imagens fotográficas. As histórias em quadrinhos, por outro lado, trazem um universo mais fantasioso, desenvolvido a partir de desenhos e com a impressão de movimentos sendo indicada e compreendida através da correta leitura de sua ligação de quadros, podendo ter o aspecto caricatural ou exagerado como um elemento de sua linguagem. McCloud (1995) destaca a relação com ícones menos realistas e mais abstratos como um dos componentes que permite maior aproximação dos leitores com uma amplitude de possibilidades e ideias. As histórias em quadrinhos, nesse caso, transitam por uma tríade entre o realismo, a linguagem e o plano das figuras; ou seja, a similaridade com a natureza e o mundo físico, o simbolismo e as possibilidades de abstracionismo de sua linguagem.

O avanço tecnológico, como apontado anteriormente, permite maior desenvolvimento do processo de transposição do quadrinístico para o fílmico. A reprodução e/ou construção de determinadas criações é facilitada com o avanço dos efeitos de computação digital. Ainda assim, essa questão não recai apenas no viés de possibilidades criativas através da evolução do aparato maquínico de um dos meios. Um elemento essencial continua sendo a compreensão das similaridades e diferenças entre ambas as linguagens, em busca de formas de transposição que permitam tal diálogo se dê da melhor forma possível. Nesse sentido, o processo de transpor a fantasia das histórias em quadrinhos para o realismo cinematográfico também é um caminho de experiências e tentativas de adequação. É importante destacar que o universo fantasioso dos quadrinhos não equivale à fantasia enquanto gênero cinematográfico.

A "fantasia”, ou o "fantástico", configura um gênero cinematográfico que trabalha a concepção de um universo diferente do que vivemos, em que suas explicações recaem, com frequência, em elementos mágicos e/ou mitológicos (Nogueira 2010). O que separa essa explicação do fantástico ou da fantasia enquanto gênero cinematográfico e o universo fantasioso das histórias em quadrinhos é a própria concepção de como desenvolver essa fantasia no cinema. $\mathrm{Na}$ "fantasia" enquanto gênero, 
temos esse componente imaginativo enquadrado dentro de regras de uma linguagem específica de um recurso audiovisual que exibe os movimentos e ações em sua tela de uma forma realística e encenada em um local real (independentemente de ser estúdio, chroma key ou locação real) com participantes reais (normalmente atores). Assim, o aspecto da impressão de realidade cinematográfica ainda se encontra em sua gênese. Mesmo com uma irrealidade nas regras desse universo, há a necessidade de adequação desses elementos aos corpos dos atores, aos cenários e suas proporções e ao próprio ritmo do filme, que costuma ter uma relação direta com as expectativas de seus espectadores. Assim, esta é uma fantasia controlada e adequada a uma linguagem cinematográfica que possui sua ontologia em um "realismo" fotográfico. Inversamente, as histórias em quadrinhos possuem uma maior liberdade: o universo fantasioso recai em uma outra linguagem em que os limites costumam ser muito mais flexíveis. Basta pensar em alguns dos atos mais exagerados do personagem Hulk, que já chegou a pular até a órbita Marte (Hickman 2014) e a derrubar florestas com um sopro de ar (Matio e Buscema 1982), entre diversas outras realizações absurdas; ou na própria concepção do personagem Galactus, um ser que devora planetas.

A distância entre as linguagens apresentava uma lacuna entre as transposições, limitando-as a alguns casos de personagens e arcos narrativos que conseguissem se adaptar bem à linguagem cinematográfica. Dessa forma, a ultrapassagem desta lacuna é conseguida através de experimentações em que a adequação é testada em diferentes histórias. Pascal Lefévre (2007) desenvolve uma resumida, porém cuidadosa, descrição das semelhanças e diferenças entre os meios em questão, ensaiando, a partir de uma investigação ontológica, alguns motivos pelos quais esse diálogo apresentaria uma série de problemas. O autor lista o acréscimo ou corte de material, as características específicas de cada meio, a dificuldade de transformar desenhos em fotogramas e a importância do som no filme e do silêncio nos quadrinhos como as quatro principais questões de sua argumentação. Apesar de assertivo nas descrições e análises, Lefévre desenvolve seu ensaio em um momento em que as transposições já alcançavam maiores bilheterias e repercussões críticas, mas ainda se encontravam em um período de experimentação de linguagens. Basta lembrar que Iron Man (o primeiro filme do universo expandido Marvel), assim como The Dark Knight, surgiriam apenas em 2008, abrindo caminho para maiores bilheterias e melhores repercussões 
críticas. Em um curto espaço de tempo, o que o autor descreve como problemático iria se consolidar como uma tendência fílmica de enorme sucesso. Lefévre indica a importância de assistir a um filme sem uma cobrança de fidelidade ao material original, compreendendo que se tratam de linguagens diferentes que apresentam, em última instância, produtos diferentes. Essa chave de compreensão parece óbvia, mas é direcionada principalmente aos fãs do material original, que, segundo o autor, costumam se apegar mais a expectativas muito específicas. Assim, percebemos que o foco ontológico não é exclusivo, visto que a construção de seu raciocínio se inicia a partir da recepção (sobretudo dos fãs).

Liam Burke (2015), por outro lado, aposta na popularidade desse processo, apontando para o atual momento como "a era de ouro das filmagens de histórias em quadrinhos”. É esse o título do primeiro capítulo do seu livro, que fornece uma variedade de dados que corroboram sua afirmativa. Ao longo do livro, através de levantamentos sobre estudos de adaptação e de um desenvolvimento cauteloso de seu recorte e opções metodológicas, o autor debruça-se sobre um amplo repertório das transposições ao longo da história do cinema. A pesquisa de Burke possui foco maior na investigação dessa hipótese e na de que as transposições fílmicas de histórias em quadrinhos são um novo gênero cinematográfico. Já em sua introdução, percebe-se a utilização de teorias sobre adaptação, direcionando sua escrita, a qual se preocupa, inclusive, com a indicação das diferentes formas de adaptação e suas categorias de análise.

As pesquisas de Lefévre e Burke foram feitas nos últimos vinte anos, mas em momentos rigorosamente diferentes (2007 e 2015). Enquanto o primeiro se preocupava em apontar os problemas desse processo que estava em seu início (se pensarmos sob o viés mercadológico recente), o segundo se deparava com um corpus analítico mais consolidado enquanto fenômeno de grande repercussão financeira e de tendência hollywoodiana. Assim, é natural que os trabalhos pareçam se confrontar em uma primeira instância. Contudo, acreditamos que os autores oferecem leituras complementares que muitas vezes dialogam e se completam e em outros momentos apenas revelam dois lados de um mesmo objeto.

As transposições de histórias em quadrinhos de super-heróis são um fenômeno que se construiu como um sucesso financeiro e de crítica, além de uma tendência cinematográfica contemporânea, a partir de 
uma série de experimentações e compreensões das linguagens e possibilidades de ambos os meios. Além disso, é necessário destacar toda importância de um determinado contexto específico capitalista e neoliberal, atrelado às questões políticas, ideológicas e produtivistas dos Estados Unidos após 11 de setembro de 2001, como visto no interessante estudo de Dan Hassler-Forest (2012) ou nos ensaios de Jason Read (2017) sobre a nova concepção de vilania que vemos no cinema atual. Ambos demonstram como o cenário que se desenvolve no país após o atentado fragiliza algumas noções de segurança e permite o crescimento de um fenômeno de busca de um imaginário heroico que auxilia a consolidação dos personagens dos quadrinhos. As propostas dos autores recaem mais em uma análise dos contextos sociopolíticos e suas demandas econômicas no cenário estadunidense do que nos elementos mais relacionados à linguagem ou às similaridades e diferenças em termos de conteúdo que este artigo apresenta. No entanto, destacam um elemento essencial no debate sobre a popularidade dos super-heróis de histórias em quadrinhos na atualidade - que também é apontado por Burke (2015) através de alguns teóricos e de trechos de entrevistas com alguns produtores e diretores dos filmes em questão.

O cenário atual conta com um momento de maior experimentação das possibilidades estéticas e narrativas das transposições, assim como com uma contínua utilização de algumas fórmulas de sucesso. Recentemente, percebemos uma tendência que aparenta uma busca maior por uma fidelidade ao material original e uma aproximação maior à estética quadrinística, como aponta Morton (2016). Essa "fidelidade" sempre deve ser analisada com um certo cuidado, pois o processo de transposição em si já implica em variadas modificações necessárias ou pautadas em decisões artísticas, financeiras, mercadológicas, ou outras. Se, de um lado, os primeiros filmes do universo Marvel - que podem ser vistos como um dos marcos iniciais para a criação dessa indústria de sucesso - apresentavam um grau de relativo realismo (dentro dos parâmetros do gênero) um pouco maior, de outro lado, a boa recepção do público tem permitido ousadias maiores em transpor os elementos mais fantasiosos das histórias em quadrinhos para as telas. Basta pensarmos em exemplos como o primeiro $X$-Men (2000) - que trazia a caracterização de seus personagens com uniformes pretos de couro, fugindo da versão colorida das histórias em quadrinhos, e cenas de luta coreografadas de forma similar às dos filmes de ação e artes marciais. É outro exemplo desta ousadia Iron Man (2008), que apresentava seu 
personagem central relacionado às indústrias armamentistas e de tecnologia robótica, promovendo feitos exagerados dentro dessas perspectivas, mas ainda ancorados em possibilidades cênicas e diegéticas comuns aos gênero da ação, aventura e ficção científica. Mas, à medida que a aceitação do público se revelou positiva, vemos essa série de filmes explorando um universo fantasioso maior e se tornando mais coloridos (o que dialoga com o aspecto imagético das histórias em quadrinhos). A comparação entre Iron Man e as recentes produções cinematográficas da mesma franchise de heróis de quadrinhos, como Avengers: Infinity War (2018) e Avengers: Endgame (2019), demonstra um trajeto em que o "realismo" 14 cinematográfico se encontra cada vez mais com o universo mais fantasioso das histórias em quadrinhos. Assim, a repercussão crítica dos fãs de quadrinhos também parece se encontrar em maior sintonia com a repercussão geral das bilheterias dos filmes.

$\mathrm{Ou}$ seja, a linguagem cinematográfica continua funcionando num processo de tentativa e erro e aceitação do público. Através de variadas experimentações, a união entre o realismo cinematográfico e a fantasia quadrinística parece encontrar seu ponto certo em um momento em que ambas as indústrias trabalham em conjunto, aproveitando as oportunidades mercadológicas surgidas. Ao mesmo tempo que o cinema tem apresentado filmes cada vez mais fantasiosos e similares ao material original das histórias em quadrinhos, uma outra vertente de experimentação tem reconfigurado personagens do universo dos super-heróis através uma estética mais próxima de dramas urbanos com forte imersão em questões sociopolíticas, como no filme Joker de 2019. Ao invés de esgotar suas possibilidades criativas, as transposições de histórias em quadrinhos têm se destacado com certo vigor como uma ampla fonte de material criativo para o cinema.

\footnotetext{
${ }^{14}$ A concepção de "realismo" no cinema possui uma longa tradição de debate entre as correntes "realistas" e "formativas" da teoria do cinema (Andrew 2002). No entanto, para fins metodológicos, utilizamos o conceito de realismo enquanto postura e método de Pellegrini (2008), apontado no início do artigo. Baseados nessa articulação, consideramos a concepção de realidade cinematográfica não como uma extensão do nosso cotidiano ou da natureza, e sim como uma compreensão do que a linguagem cinematográfica e os filmes de cada época atribuem como real no espaço cênico e diegético.
} 


\section{Considerações finais}

O cinema possui um longo histórico como objeto de estudo da comunicação. Em uma vertente um pouco mais tímida, porém também de extrema relevância, as histórias em quadrinhos vêm ganhando crescente espaço no campo das pesquisas acadêmicas. Os estudos sobre as transposições fílmicas dos quadrinhos, contudo, ainda se encontram em um período mais embrionário. Apesar dos livros de Burke (2015) e Morton (2016), de uma forma geral as publicações sobre o assunto se resumem mais a artigos acadêmicos, capítulos de livros e análises de casos mais específicos, como o próprio Burke (2015) aponta em sua introdução. Assim, nos deparamos com um terreno fértil de pesquisa.

Entretanto, essa extensa transposição cinematográfica do conteúdo narrativo das histórias em quadrinhos de super-heróis se encontra como um fenômeno comunicacional atual e gerador de orçamentos cada vez maiores com públicos em crescente ascensão. Além do espaço de audiência que promove, encontra-se com boa aceitação crítica, como podemos ver com a obra Black Panther (2018) em sua recente aparição em diversas modalidades da premiação dos óscares. O filme foi indicado em 7 modalidades, tendo ganhado 3.

Em 2019, Joker, de Todd Phillips, tem o vilão das histórias de Batman como seu protagonista. Neste sucesso de crítica e público, o diretor cria uma obra que dialoga com a filmografia de Martin Scorsese, sobretudo em produções consagradas como Taxi Driver (1976) e The King of Comedy (1982). Curiosamente, Scorsese havia estado sob os holofotes do debate sobre transposições de quadrinhos para o cinema, tecendo críticas aos filmes de franquia da Marvel. ${ }^{15} \mathrm{O}$ cenário em que a polêmica surge é marcado por um momento em que os estúdios cinematográficos tradicionais decidem não financiar o alto orçamento do projeto The Irishman (2019), fazendo-o ser produzido pela Netflix, via streaming. Com argumentos que indicam a falta de inovação dos filmes baseados em histórias em quadrinhos, Scorsese parece demonstrar um certo elitismo em seu discurso, principalmente tendo em conta o modo como uma produção como Black Panther (2018) se tornou um marco em termos de representatividade nos filmes de grande orçamento e de bilheteria em Hollywood. Estudos prévios, como os realizados por

\footnotetext{
${ }^{15}$ https://www.nytimes.com/2019/11/04/opinion/martin-scorsese-marvel.html (consultado em 10 de fevereiro de 2021).
} 
Wrublevski e Garcia (2019) e Garcia, Lima e Lopes (2020), defendem a importância do processo de aumento de espaço para minorias em termos de representatividade, protagonismo, e até mesmo de contratação promovido pelas grandes produções cinematográficas baseadas em histórias em quadrinhos. No ano em que Scorsese criticava os filmes baseados em histórias em quadrinhos, Joker se destacou como a produção com mais indicações na cerimônia dos óscares, tendo recebido 11, enquanto The Irishman recebia 10. O filme de Todd Phillips acabou vencendo dois óscares, além de outras premiações de outros festivais. Enquanto isso, o filme de Scorsese, apesar de toda sua divulgação e investimento, acabou não ganhando em qualquer categoria.

Joker caminha em um sentido contrário à estética fantasiosa das grandes transposições de histórias em quadrinhos de super-heróis do Universo Marvel e DC, experimentando uma nova amplitude de possibilidades. Com uma carga dramática mais intensa, contando com uma aclamada atuação do ator Joaquin Phoenix no papel principal, seu arco procura uma maior relação com questões sociais alinhada com um tipo de cinema mais realista. Além disso, promove um questionamento ao próprio estatuto do super-herói, dando visibilidade ao clássico vilão por uma óptica mais humanista que problematiza os binarismos sociais e os distanciamentos por ele produzidos. Assim, ao invés de se esgotar como fórmula cinematográfica, ou de se estagnar em um eterno processo de continuação de franquias, as transposições cinematográficas de histórias em quadrinhos parecem se reinventar e explorar novas possibilidades.

O cinema e as histórias em quadrinhos possuem algumas similaridades em termos de linguagem e se relacionam de variadas formas ao longo da história. Entre elas, as transposições das histórias em quadrinhos acabam se destacando como uma das principais formas de diálogo entre os meios. Explorando suas vertentes em comum em termos de narrativa e seus elementos gramaticais similares de imagem e movimento, as experiências ao longo do tempo permitiram que suas diferenças pudessem ser alinhadas para que esse atual mercado fosse criado com uma constante produção de grandes bilheterias se firmando na indústria. Enquanto isso, o sucesso de crítica parece se tornar também outro elemento comum nesses filmes, indicando novas possibilidades de criação e demonstrando que as histórias em 
quadrinhos se tornam, cada vez mais, uma das principais fontes de inspiração para o cinema.

\section{Referências}

Anderson, Chris. 2006. A Cauda Longa. Rio de Janeiro: Elsevier Editora.

Andrew, James Dudley. 2002. As Principais Teorias do Cinema: Uma introdução. Rio de Janeiro: Jorge Zahar Editora.

Aumont, Jacques. 2008. Moderno? Por que o Cinema Se Tornou a Mais Singular das Artes. Campinas: Papirus.

Bauman, Zygmunt. 2001. Modernidade Líquida. Rio de Janeiro: Jorge Zahar Editora.

Bernadet, Jean-Claude. 1985. O que é Cinema. Editora Brasiliense.

Blumer, Herbert. 1933. Movies and Conduct. Nova Iorque: Macmillan \& Company.

Bolter, Jay David, e Grusin, Richard. 2000. Remediation: Understanding New Media. Cambridge: The MIT Press.

Bordwell, David. 2005. "O cinema clássico hollywoodiano: normas e princípios narrativos”. In Teoria Contemporânea do Cinema, vol. II, editado por Fernão P. Ramos, 277-301. São Paulo: editora Senac.

Brésio, Sabrina da Paixão. 2016. Nas Trilhas do Herói. Histórias em Quadrinhos \& Itinerários de Construção. Dissertação de Mestrado. São Paulo: USP, Faculdade de Educação.

Burke, Liam. 2015. The Comic Book Film Adaptation: Exploring modern Hollywood's leading genre. Jackson: University Press of Mississipi.

Campbell, Joseph. 1989. O Herói de Mil Faces. São Paulo: Cultrix.

Costa, Flávia Cesarino. 2005. O Primeiro Cinema: Espetáculo, Narração, Domesticação. Rio de Janeiro: Azogue Editorial.

Eco Umberto. 2006. Apocalípticos e Integrados. São Paulo: Perspectiva.

Eisner, Will. 1989. Quadrinhos e Arte Sequencial. São Paulo: Martins Fontes.

Escosteguy, Ana Carolina. 2010. "Estudos Culturais". In Teorias da Comunicação: Conceitos, escolas e tendências, editado por Antônio 
Hohlfeldt, Luiz C. Martino, e Vera Veiga França, 151-170. Petrópolis, RJ: Vozes.

Felinto, Erick. 2006. “Cinema e Tecnologias Digitais”. In História do Cinema Mundial, editado por Fernando Mascarello, 413-428. Campinas: Papirus Editora.

Garcia, Yuri, Lima, Ellen Alves, e Lopes, Luccas. 2020. “A Real Presença em Wakanda: 'Pantera Negra' e a Representatividade na indústria cinematográfica”. In Roteiro X: The X-Script, editado por Gláucia Davino e Fernanda Bellicieri, 165-176. São Paulo: Pomello Digital.

Garcia, Yuri, Monsores, Emanuelli da Silva, e Mangia, Gustavo. 2020. "Evoluções e transformações no gênero da ação: John Wick e a influência das HQs". In Roteiro X: The X-Script, editado por Gláucia Davino e Fernanda Bellicieri, 347-359. São Paulo: Pomello Digital.

Geada, Eduardo. 1998. Os Mundos do Cinema: Modelos dramáticos e narrativos no período clássico. Lisboa: Editorial Notícias.

Gordon, Ian. 1998. Comic Strips and Consumer Culture: 1890-1945. Washington: Smithsonian Institution Press.

Gunning, Tom. 2006. "The cinema of attractions: Early film, its spectator and the avant-garde". In The Cinema of Attractions Reloaded, editado por Wanda Strauven, 381-388. Amsterdam: Amsterdam University Press.

Hassler-Forest, Dan. 2012. Capitalist Superheroes: Caped crusaders in the neoliberal age. Washington: Zero Books.

Hickman, Jonathan. 2014. Avengers. vol 5 24. NOW. Marvel.

Jenkins, Henry. 2009. Cultura da Convergência. São Paulo: Editora Aleph.

Jung, Carl Gustav. 2018. Os Arquétipos e o Inconsciente Coletivo. Rio de Janeiro: Vozes.

Lefévre, Pascal. 2007. "Incompatible Visual Ontologies?: The problematic adaptation of drawn images". In Film and Comic Books, editado por Ian Gordon, Mark Jancovich, e Matthew P. McAllister. University Press of Mississippi.

Machado, Arlindo. 2014. Pré-cinemas e Pós-cinemas. Campinas: Papirus.

Martin, Marcel. 2011. A Linguagem Cinematográfica. São Paulo: Brasiliense. 
Martins, Fernanda A. C.. 2006. “Impressionismo Francês”. In História do cinema mundial, editado por Fernando Mascarello, 89-108. Campinas: Papirus Editora.

Matio, Bill e Buscema, Sal. 1982. Incredible Hulk vol 1 273. Marvel.

McCloud, Scott. 1995. Desvendando os Quadrinhos. São Paulo: Makron Books.

McLuhan, Herbert Marshall. 2007. Os Meios de Comunicação como Extensões do Homem. São Paulo: Cultrix.

Messias, José. 2012. A Construção da Figura do Herói nos Mangás e Comics: Uma análise comparativa entre samurais e super-heróis. Dissertação de Mestrado, Programa de Pós-Graduação em Comunicação. Rio de Janeiro: UERJ, PPGCom.

Morton, Drew. 2016. Panel to the Screen: Style, American Film, and Comic Books during the Blockbuster Era. Jackson: University Press of Mississippi.

Moya, Álvaro. 2013. "Pioneiro dos quadrinhos brasileiros, como desenhista e pesquisador". In Os Pioneiros no Estudo de Quadrinhos no Brasil, editado por Valdomiro Vergueiro, Paulo Ramos, e Nobu Chinen, 28-35. São Paulo: Editora Criativo.

Nogueira, Luís. 2010. Manuais de Cinema II: Géneros Cinematográficos. LabCom.

Pellegrini, Tânia. (2008). "Realismo: postura e método". Letras De Hoje, 42 (4): 137-155.

Read, Jason. 2017. "Quatre textes sur les films de superhéros". Articles, Web-revue des industries culturelles et numériques. Disponível em: http://industrie-culturelle.fr/industrie-culturelle/films-superheros-jason-read/

Santos, Roberto Elísio. 2015. “Aspectos da linguagem, da narrativa e da estética das histórias em quadrinhos: convenções e rupturas”. In A linguagem dos quadrinhos: estudos de estética, linguística e semiótica, editado por Waldomiro Vergueiro e Roberto Elísio dos Santos, 22-47. São Paulo: Criativo.

Singer, Marc. 2018. Breaking the Frames: Populism and Prestige in Comics Studies. Austin: University of Texas Press.

Vergueiro, Valdomiro, Ramos, Paulo, e Chinen, Nobu (orgs). 2013. Os Pioneiros no Estudo de Quadrinhos no Brasil. São Paulo: Editora Criativo. 
Vergueiro, Valdomiro. 2015. “A contribuição de Antonio Luiz Cagnin aos estudos sobre a linguagem dos quadrinhos no Brasil”. In $A$ linguagem dos quadrinhos: estudos de estética, linguística $e$ semiótica, editado por Waldomiro Vergueiro; Roberto Elísio dos Santos, 08-21. São Paulo: Criativo.

Wrublevski, Matilde e Garcia, Yuri. 2019. "Mulher Maravilha e o protagonismo feminino”. In Narrativas Difusas em Suportes Sensíveis, editado por Gláucia Davino, 288-299. São Paulo: Editora Corpo Texto.

\section{FILMOGRAFIA}

American Splendor [feature film] Dir. Shari Springer Berman e Robert Pulcini. Good Machine/Dark Horse Entertainment et al., USA, 2003. 101 mins.

Art School Confidential [feature film] Dir. Terry Zwigoff. United Artists/Sony Pictures Classics et al, USA, 2006. 102 mins.

Avengers: Infinity War [feature film] Dir. Anthony Russo, Joe Russo. Marvel Studios/Jason Roberts Productions et al., USA, 2018. 159 mins.

Avengers: Endgame [feauture film] Dir. Anthony Russo, Joe Russo. Marvel Studios/Walt Disney Pictures et al., USA, 2019. 181 mins.

Batman [feature film] Dir. Tim Burton. Warner Bros./The GuberPeters Company et al., USA/UK, 1989. 126 mins.

Batman Returns [feature film] Dir. Tim Burton. Warner Bros./PolyGram Filmed Entertainment et al., USA/UK, 1992. 126 mins.

Batman Forever [feature film] Dir. Joel Schumacher. Warner Bros./Polygram Filmed Entertainment et al., USA/UK, 1995. 121 mins.

Batman \& Robin [feature film] Dir. Joel Schumacher. Warner Bros./Polygram Filmed Entertainment et al., USA/UK, 1997. 125 mins.

Black Panther [feature film] Dir. Ryan Coogler. Marvel Studios/Walt Disney Pictures et al., USA, 2018. 134 mins.

Dennis the Menace [feature film] Dir. Nick Castle. Warner Bros./Hughes Entertainment et al., USA, 1993. 94 mins. 
Era uma Vez na América [feature film] Dir. Sergio Leone. The Ladd Company/Warner Bros. et al., Italy/USA, 1984. 229 mins.

Era uma Vez no Oeste [feature film] Dir. Sergio Leone. Rafran Cinematografica/San Marco et al., Italy/USA, 1968. 165 mins.

Flash Gordon [feature film] Dir. Mike Hodges. Starling Films/Famous Films et al., UK/Italy et al., 1980. 111 mins.

Ghost World [feature film] Dir. Terry Zwigoff. United Artists/Granada Film Productions et al., USA/UK et al., 2001. 111 mins.

Iron Man [feature film] Dir. Jon Favreau. Paramount Pictures/Marvel Enterprises et al., USA/Canada, 2008. 126 mins.

Joker [feature film] Dir. Todd Phillips. Warner Bros./Village Roadshow Pictures et al., USA/Canada. 2019. 122 mins.

John Wick [feature film] Dir. Chad Stahelski, David Leitch (uncredited). Summit Entertainment/Thunder Road Pictures et al., USA/UK et al., 2014. 101 mins.

John Wick: Chapter 2 [feature film] Dir. Chad Stahelski. Summit Entertainment/Thunder Road Pictures et al., USA/Italy et al., 2017. 122 mins.

John Wick: Chapter 3 - Parabellum [feature film] Dir. Chad Stahelski. Lionsgate/Summit Entertainment et al., USA, 2019. 130 mins.

L'arroseur arrosé [short film] Dir. Alice Guy, Louis Lumière. Lumière/Société des Etablissements L. Gaumont, France, 1895. 1 min.

Logan [feature film] Dir. James Mangold. Twentieth Century Fox/Marvel Enterprises et al., USA, 2017. 137mins.

Richie Rich [feature film] Dir. Donald Petrie. Warner Bros./Silver Pictures et al., USA, 1994. 95 mins.

Sin City [feature film] Dir. Frank Miller, Robert Rodriguez, Quentin Tarantino. Dimension Films/Troublemaker Studios et al., USA, 2005. 124 mins.

Spider-Man [feature film] Dir. Sam Raimi. Columbia Pictures/Marvel Enterprises et al., USA, 2002. 121 mins.

Superman [feature film] Dir. Richard Donner. Dovemead Films/Film Export A.G. et al., USA/UK et al., 1978. 143 mins.

Superman II [feature film] Dir. Richard Lester, Richard Donner (uncredited). Dovemead Films/Film Export A.G. et al., USA/UK et al., 1980. 127 mins. 
Superman III [feature film] Dir. Richard Lester. Dovemead Films/Cantharus Productions et al., UK/USA, 1983. 125 mins.

Superman IV: The Quest for Peace [feature film] Dir. Sidney J. Furie. Cannon Films/Warner Bros. et al., UK/USA, 1987. 90 mins.

Taxi Driver [feature film] Dir. Martin Scorsese. Columbia Pictures/Bill/Phillips et al., USA, 1976. 114 mins.

Teenage Mutant Ninja Turtles [feature film] Dir. Steve Barron. 888 Productions/Golden Harvest et al., USA/Hong Kong, 1990. 93 mins.

The Dark Knight [feature film] Dir. Christopher Nolan. Warner Bros./Legendary Entertainment et al., USA/UK, 2008. 152 mins.

The Good, the Bad and the Ugly [feature film] Dir. Sergio Leone. Produzioni Europee Associate (PEA)/Arturo González Producciones Cinematográficas et al., Italy/Spain et al, 1966. 161 mins.

The Irishman [feature film] Dir. Martin Scorsese. Tribeca Productions/Netflix et al., USA, 2019.209 mins.

The King of Comedy [feature film] Dir. Martin Scorsese. Embassy International Pictures/Twentieth Century Fox et al., USA, 1982. 119 mins.

The Matrix [feature film] Dir. Lana Wachowski, Lilly Wachowski. Warner Bros./Village Roadshow Pictures et al., USA, 1999. 136 mins.

Wonder Woman [feature film] Dir. Patty Jenkins. Warner Bros./Atlas Entertainment et al., USA/UK, 2017. $141 \mathrm{~min}$.

$X$-Men [feature film] Dir. Bryan Singer. Twentieth Century Fox/Marvel Enterprises et al., USA, 2000. 104 mins. 


\title{
Filmic Transpositions of Comic Books: Theorising the relationship between the languages of cinema and comics
}

\begin{abstract}
This article aims to assess the relationship between the languages of cinema and comics. Comic book adaptations - especially of superhero stories - have become a major market for the film industry. These productions are usually accompanied by a large budget and high box office numbers, establishing themselves among the biggest blockbusters in film history. Thus, this trend seems to be gaining increasing importance in Hollywood. In addition to the financial factor, which stands out as an essential element in the choices of major cinematographic productions, the films in question seem to establish new possibilities, having started a process that generates greater critical acceptance. An investigation of this phenomenon in its most grammatical configuration can usher in hypotheses pointing towards why the contemporary context appears to be ideally suited for comics to be transposed to cinema.
\end{abstract}

KEYW ORDS Cinema; comic books; transpositions; language; theory.

Recebido a 9-08-2020. Aceite para publicação a 18-02-2021.

aniki Ensaios | Essays 